ÁREA ABIERTA No 29. JULIO 2011

Referencia: AA29.1107.145

"NUEVAS PERSPECTIVAS DE LA PUBLICIDAD EN EL TELÉFONO MÓVIL"

AUTORES: Dra. María Luisa GARCÍA GUARDIA , Dr. José Ignacio NIÑO y Dra. Patrica NÚÑ̃E GÓMEZ. UNIVERSIDAD COMPLUTENSE DE MADRID

\title{
NUEVAS PERSPECTIVAS DE LA PUBLICIDAD EN EL TELÉFONO MÓVIL. Relación de los usuarios y la tecnología
}




\section{RESUMEN}

La comunicación persuasiva tiene en el terminal móvil un medio para desarrollar eficaces estrategias basadas en el potencial de las nuevas tecnologías. Es un medio interactivo que ofrece una información muy detallada del usuario y por tanto propone contenidos muy afines. Conocer los diferentes modos y contenidos publicitarios que se dan en el teléfono móvil es conocer las nuevas formas que adopta la publicidad en la era digital, marcada por las nuevas tecnologías. Este artículo está basado en un estudio aplicado sobre telefonía móvil y la construcción de contenidos persuasivos interactivos, así como el consumo que realiza un determinado target, en este caso, nativos digitales, de la publicidad.

Palabras clave: Telefonía móvil, audiencias, publicidad interactiva, marketing de proximidad, nuevas tecnologías, nativos digitales.

Persuasive communication finds a means to develop effective strategies based on the potential of new technologies in the mobile terminal. It is an interactive media that provides a very detailed user information and therefore, offers very accurate taste-related content. Getting to know the advertising means and contents in the mobile terminal is the way to understand the new methods advertising is adopting in the digital era, an era that is being shaped by new technologies. This article is based on an applied study on mobile communication, and the building of interactive and persuasive content, as well as on the consumption of advertising that a specific target, in this case, digital natives, have.

Mobile phone, interactive advertising, proximity marketing, audience, new technologies, digital natives. 


\section{Introducción}

La evolución tecnológica experimentada en los últimos 50 años, es el factor que no solo está modificando los pilares de la sociedad moderna, sino que está redefiniendo los patrones de comportamiento de los individuos en muchos aspectos, pero muy especialmente en el ámbito de las comunicaciones y en sus capacidades para interrelacionarse con el entorno. Estos profundos cambios han llevado a Duderstadt (2002) a afirmar que la sociedad está experimentando una frenética revolución que ha dado origen a la Sociedad de la Información. Este es un concepto hoy en día de uso generalizado, pero que sin embargo tiene numerosos antecedentes en el tiempo, y ya J. Naisbitt (1990) cita este término y apunta muchas de sus características actuales.

Hablamos de Sociedad de la Información, pero también sería válido hablar de Sociedad del Conocimiento o Sociedad del Aprendizaje. Para autores como P.F. Drucker el conocimiento es esencial y habría que posicionarlo como elemento generador de riqueza en el marco de una teoría económica avanzada.

Por tanto, entendemos que las sociedades modernas necesitan estar informadas, necesitan conocer y necesitan aprender, porque así desarrollan su nivel de bienestar. Si en paralelo a estas necesidades, los instrumentos y mecanismos por los que se satisfacen se desarrollan tecnológicamente, es fácil asumir el gran auge que estos tendrán.

Y de algún modo, todos estos conceptos nos llevan a un lugar común que apunta unidireccionalmente hacía un mismo objetivo: las TICs (Tecnologías de la Información y la Comunicación), que podemos definir como un conjunto de productos y procesos que se elaboran con herramientas de última generación surgidas del ámbito de la informática, soportes de la información y canales de comunicación y que se relacionan con el almacenamiento, procesamiento y transmisión digital de la información.

Para McLuhan (1996), el impacto de estas tecnologías es trascendental para la sociedad y nos invita a una reflexión sobre los medios de comunicación y las TICs como extensión de los seres humanos. En su opinión, el desarrollo tecnológico está cambiando al mundo y por tanto se está modificando la sensibilidad y la conciencia humana. La Humanidad tiene que ir preparándose para asumir esta imparable transformación y establecer las normas que regulen el uso lícito de estas poderosas herramientas.

La tecnología está cada vez más presente en la vida de las personas y Davis, F. \& Venkatesh, V. (1989) en su "Teoría de la Aceptación de la Tecnología" explican como los seres humanos estamos preparados para aceptar cualquier nueva tecnología siempre y cuando entendamos que este nuevo reto supone facilitarnos determinadas tareas. Podemos afirmar que el esquema básico en el proceso de adopción de innovaciones se divide en tres etapas:

"En la primera, cuando comienza a ofrecerse el nuevo producto solo es adquirido por los consumidores más innovadores ya que se percibe como novedoso y sus aplicaciones potenciales no se comprenden plenamente. En la segunda, comienza a generalizarse su uso. A medida que la innovación se va consolidando y, poco a poco, se va considerando que sus características son superiores a las de los productos preexistentes comienza a sustituirlos. La vieja tecnología va haciéndose progresivamente cada vez más difícil de encontrar. Finalmente, en la tercera, la sociedad se acostumbra plenamente al nuevo producto y pasa a ser considerado una necesidad. Los consumidores no necesitan justificar su utilidad o racionalizar su deseo por el producto" Rogers (1992).

No siempre el acceso a los nuevos usos tecnológicos es fácil y en ocasiones pueden conducir a situaciones de exclusión social o a generar grupos marginados de los que tenemos en la actualidad un claro ejemplo en los analfabetos digitales, individuos que no han tenido acceso al ordenador o a internet por razones básicamente de índole 
económica, cultural o simplemente por tener actitudes contrarias a la tecnología (tecnófobos, marginados, inactivos).

Este aspecto es definitivo si constatamos que los países con un nivel de desarrollo social muy bajo y sin recursos para desplegar una infraestructura tecnológica capaz de llegar a todos, se encuentran sin posibilidades de evolucionar y lo que es peor, dada la rapidez con que las tecnologías cambian, siempre irán por detrás y no podrán subirse a este potente motor de progreso. Así es como se genera la llamada brecha digital (Trejo, 2006) que cada vez amplia más las diferencias entre el mundo del bienestar y el mundo del subdesarrollo.

Al margen de estas exclusiones que entrarían en otro campo de estudio, las TICs son una realidad en constante proceso de desarrollo. Estas tecnologías son múltiples y con diferentes aplicaciones, pero unidas por un nexo común que no es otro que poner al servicio de los individuos potentes herramientas para facilitarles la cobertura de sus necesidades de comunicación, información y aprendizaje, pero que además sean fáciles de usar para que no existan barreras en su aceptación. La Teoría Universal de Valores y La Teoría de la Motivación Humana se han ocupado del estudio de las necesidades que llevan a los individuos a adquirir determinados productos y han establecido una fuerte correlación entre el grado de deseo y el grado de innovación tecnológica. Los individuos nos sentimos atraídos y motivados por aquellos objetos que percibimos como avanzados o útiles y los posicionamos de un modo preferente en nuestra escala de valores.

\section{Las nuevas formas de la comunicación persuasiva}

La publicidad en el teléfono móvil ha tenido que adaptarse a unos aspectos formales marcados por las particularidades de este nuevo medio de comunicación. El teléfono móvil reconstruye la publicidad, añadiendo un nuevo poso de conocimiento. Sus expresiones básicas se construyen desde la experiencia de la publicidad digital en internet, incorporando factores que son inherentes a su propia naturaleza.

El teléfono móvil es un elemento personal, que acompaña al usuario mientras desempeña las actividades de su vida cotidiana. El terminal está conectado y puede recibir estímulos comunicativos en cualquier momento, al margen de las circunstancias particulares en que se encuentre su propietario en ese momento.

La publicidad en el móvil, en aquellas campañas en las que el usuario actúa como elemento pasivo, debe ser respetuosa y no invadir al receptor. Por tanto, hablamos de permission marketing o lo que es lo mismo, de acciones de marketing que requieren permiso previo del receptor para desplegarse en la pantalla de su terminal.

En España la comunicación persuasiva en el móvil sigue las normas marcadas por la Unión Europea y se rige por un modelo de opt-in, en el que el usuario tiene que dar su consentimiento a una empresa para que utilice su número de teléfono y lo almacene en una base de datos.

Todos estos modos publicitarios en el móvil se refieren a aquellas campañas en las que el usuario recibe información por iniciativa de una compañía, y no a aquellas campañas a las que el usuario accede por voluntad propia.

En la publicidad en el teléfono móvil se dan diferentes tipos de campañas en función del rol jugado por los usuarios en el desarrollo de las mismas.

En este sentido sería interesante antes de continuar hacer mención al término Interactividad y su significado. No se aplica convenientemente a la publicidad, "pues aunque todo lo interactivo sea sobre todo digital, no todo lo digital es interactivo". (Carrillo, M.V. 2005) En este sentido, la interactividad de pende de: el tiempo real, la no demora en la respuesta y el atractivo. Carrillo materializa la experiencia interactiva del 
usuario en tres dimensiones: el control activo, la multidireccionalidad (reelaboración del feedback) y la sincronía.

La interactividad no es solo aquello que permite al receptor recibir y reaccionar a los mensajes, está en la cabeza del usuario y tiene que tener la sensación de ser escuchado y crear su propia experiencia, más que de lo tecnológico. Todo esto llevará a un cambio en las estrategias de publicidad, despertando mayor interés en el target. (Carrillo, M.V., 2005)

\subsection{Campañas}

Son campañas iniciadas desde el anunciante en las que el usuario recibe una información en forma de SMS o MMS y en la que se le incita a una acción concreta hacia una marca, producto o servicio. Estos mensajes pueden incluir desde ofertas, descuentos especiales o promociones a las que acceder con mensajes de respuesta, o bien invitar a navegar por una web móvil.

Estas campañas implican por parte del anunciante disponer de una base de datos legalizada que le permite un gran control de la acción ya que dispone de muchos datos de los receptores. Puede segmentar el público objetivo optimizando la oferta, elegir el momento que más le convenga para lanzar la acción y puede interactuar con él. Son campañas que no requieren grandes inversiones y que se pueden activar con rapidez y facilidad.

Al ser campañas donde existe interactividad, se puede controlar su eficacia y modificar la misma mientras se desarrolla en base a la información que se recibe. Por tanto, son campañas que se pueden reconducir a medida que se ejecutan con el objetivo de incrementar su efectividad. Uno de los aspectos relevantes de estas acciones es su alto grado de viralidad en cuanto el contenido es atractivo, innovador o sugerente.

\subsection{Campañas}

En este tipo de campaña el papel de los receptores es proactivo y no reactivo como en el caso de las anteriormente descritas. Según Barnes y Scornavacca (2004), son acciones de publicidad a las que los usuarios acceden a través del móvil cuando en otros medios ven una campaña de un anunciante que les invita a contestar a través del móvil. Su implementación es similar a las campañas Push, pero en este caso, el anunciante no ha iniciado la acción enviándole directamente un mensaje al terminal, sino a través de diferentes medios bien off-line $u$ on-line.

El receptor interesado en la propuesta de comunicación, accede a ella respondiendo a través de un SMS Premium (mensajes de tarificación especial) y siempre que conteste el anunciante le envía un mensaje. Se establece entonces un dialogo con el usuario que permite conocerle obtener datos muy relevantes de cara a acciones futuras.

Estas campañas no requieren base de datos, puesto que se inician en medios masivos, pero en contraposición tienen mayor coste ya que requieren una inversión en medios. Frente a las campañas Pull, son menos agresivas ya que solo participan en ellas aquellos usuarios que realmente tienen interés y esto influye decisivamente en los niveles de eficacia de las mismas.

\subsection{Mensajería: formatos}

Los formatos más utilizados en el ámbito de la publicidad móvil son los que se integran en servicios de mensajería conocidos como SMS y MMS. A pesar de que los mensajes multimedia todavía no tienen un gran alcance, cada vez tienen mayor uso gracias a sus posibilidades para combinar texto, imagen y sonido. 
Aunque su volumen en el mercado es muy pequeño respecto a los SMS, los MMS se muestra como el formato que más gustara recibir, como podemos comprobar en el gráfico:

\section{Formatos más atractivos (en \%)}

$4,2 \quad 2,4$

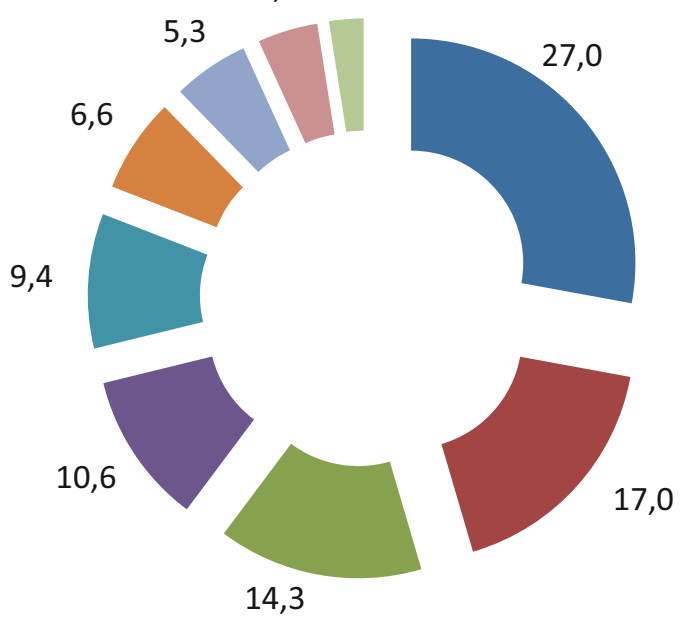

MMS audio
Vídeo patrocinado
Advergaming
Aplicación patrocinada
Interstitisal
SMS
Banner
MMS
SMS Wap Push

Fuente: Zed Digital. Estudio sobre la percepción usos y tendencias de la telefonía móvil. $4^{\circ}$ Ola Sep-2010. Muestra 4.033 internautas $14-44$ años.

Fuera de su uso publicitario, el SMS representa un fenómeno social para la gente joven, que han integrado este sistema en su forma habitual de interrelacionarse con su entorno creando un lenguaje especifico, no del gusto de todos por sus incorrecciones gramaticales, pero si ingenioso por su gran economía a la hora de pulsar caracteres.

El desarrollo del negocio de la telefonía móvil ha propiciado la creación de múltiples aplicaciones que complementan sus ya conocidas funcionalidades. La aparición de terminales inteligentes con potentes sistemas operativos permite la instalación de aplicaciones que requieren recursos avanzados. Estos "smartphones" están preparados para soportar programas en las mismas condiciones que un ordenador y trabajar con altos rendimientos.

No solo los teléfonos inteligentes reciben aplicaciones, también los convencionales disponen de una amplia gama de posibilidades, aunque con niveles de funcionamiento y prestaciones menos sofisticadas.

\subsection{Internet móvil: formatos web,}

La conexión a banda ancha incorporada por muchos terminales de última generación, da acceso al servicio conocido como internet móvil que permite la navegación web a través del teléfono. En el momento que se conecta, el entorno publicitario que vamos a encontrar es similar al que vemos cuando navegamos por internet con un ordenador, pero lógicamente con algunas particularidades.

Los teléfonos móviles tienen unos tamaños de pantalla y velocidades de conexión que obliga a las empresas a desarrollar páginas webs preparadas para estas condiciones. Los portales Wap optimizan los contenidos adaptando la información a través de un micronavegador que despliega la información de internet de una forma más efectiva para pantallas de menor tamaño y menor capacidad de memoria. Frente a la conocida 
tecnología Wap, i-Mode es una apuesta desarrollada por DOCOMO NTT a principios de siglo en Japón y que aporta mejores posibilidades para la navegación móvil. Su funcionamiento se basa en una versión de HTML para móviles que permite comprimir la información y enviar mayor número de datos que con el uso del lenguaje de programación WML empleado por la tecnología Wap.

El acceso a internet móvil habitualmente se realiza por defecto a través de portales de entrada Wap preestablecidos por el operador telefónico con objeto de controlar la navegación y generar ingresos mediante los contenidos ofrecidos. Además, la compañía telefónica juega con ventaja ya que tienen muchos datos de sus clientes (edad, sexo, provincia, facturación mensual).

Cualquiera que sea el tipo de portal en el que se introduce el usuario, este encontrará formatos publicitarios integrados, flotantes o expandibles. Los integrados son aquellos que tienen una posición fija, los expandibles son formatos integrados que aumentan de tamaño a través de un panel que se despliega y los flotantes son aquellos que cambian de posición.

En cuanto a su tecnología, estos anuncios pueden ser estáticos, dinámicos o rich media. Los estáticos son los que tienen una creatividad que no se mueve, los dinámicos se producen básicamente en lenguaje flash para incorporar movimiento y por último los rich media son aquellos que se enriquecen con contenidos audiovisuales.

También a través de la navegación móvil podemos acceder a buscadores o enlaces patrocinados que nos llevan a sitios que incorporan comunicación persuasiva, bien en el propio sitio, bien ofreciendo descargas de contenidos: videoclips, música, películas, etc. Otras campañas que pueden llegar a la pantalla del terminal son las basadas en correos electrónicos (emailing) y boletines informativos (enewsletter). En el caso del correo, el emisor envía información que generalmente incorpora enlaces a una web. El boletín tiene como objetivo principal informar al receptor, pero también puede incorporar mecanismos para llevarle a otro microsite.

\subsection{Marketing de proximidad}

Una de las formas publicitarias más novedosas aplicadas a través del teléfono móvil, es el marketing de proximidad que basa su eficacia en la posibilidad de enviar mensajes a receptores que se encuentran en el área de interés del emisor. En este campo se están desarrollando interesantes iniciativas en el ámbito de la geolocalización a través de sistemas de triangulación GSM y GPS que abren interesantes campos de actuación, pero que en el ámbito de la publicidad aún se encuentran en fase experimental.

\section{6.}

La tecnología bluetooth incorporada en los teléfonos móviles, es una tecnología de ondas de radio que permite conectar dispositivos sin necesidad de cables.

En su aplicación publicitaria, el bluetooth permite desarrollar campañas muy eficaces cuando se actúa en espacios dentro del alcance de estos dispositivos. Esta tipología de acciones se instrumenta a través de una estación emisora que lanza mensajes. Cuando esta detecta un dispositivo bluetooth activado, genera un mensaje de entrada en la pantalla de ese móvil. El usuario lo ve y puede optar por él o no.

Por ejemplo, estas campañas son muy útiles en centros comerciales donde hay mucho tráfico de personas a las que se puede invitar a entrar en las tiendas mediante ofertas exclusivas, descuentos o cualquier otra estrategia promocional.

Son acciones muy sencillas de implementar, tienen un coste muy reducido, son poco intrusivas y si el mensaje es atractivo alcanza unos niveles de conversión muy elevado. 
Frente a estas ventajas, su gran limitación esta en el gran número de usuarios que no tienen activada esta función. A continuación vemos datos sobre su uso:

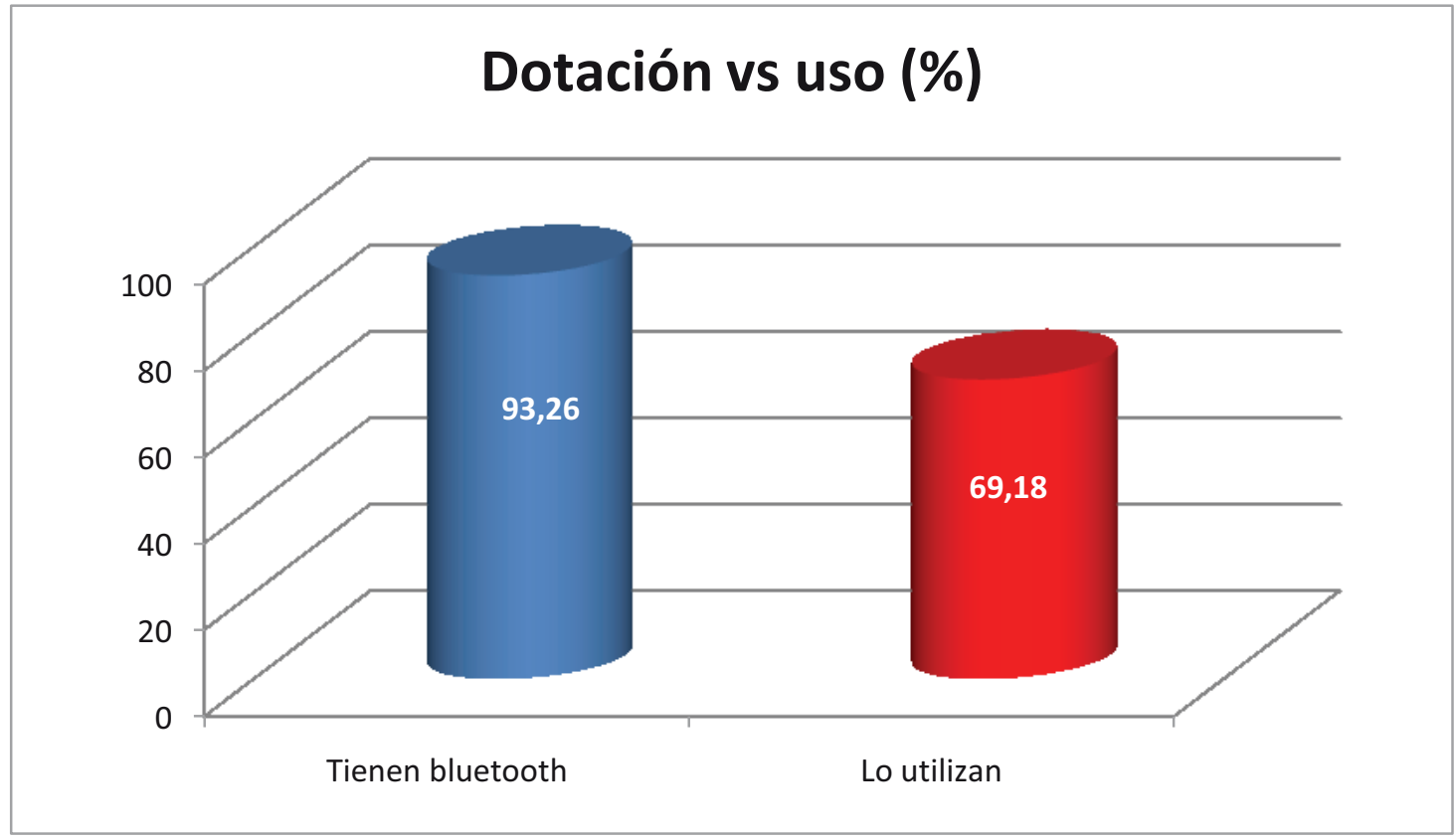

Fuente: Zed Digital. Estudio sobre la percepción usos y tendencias de la telefonía móvil. 4 Ola Sep-2010. Muestra 4.033 internautas 14-44 años.

\section{El móvil, un medio eficaz}

La estrategia publicitaria desarrolla sus acciones de comunicación a través de medios que tienen diferentes características. Una buena planificación será aquella que sea capaz de llegar al target explotando al máximo el potencial que le ofrece cada medio de comunicación.

Para la publicidad resulta esencial conocer las prestaciones de los medios, y analizar cuáles son las variables que más importancia tienen a la hora de ejecutar las campañas. Según Haghirian y Dickinger (2004), es necesario identificar los factores que determinan el éxito como medio del teléfono móvil. Muchas son las investigaciones que se realizan en este ámbito y sirven de referencia para establecer las líneas generales que conforman un medio publicitario eficaz:

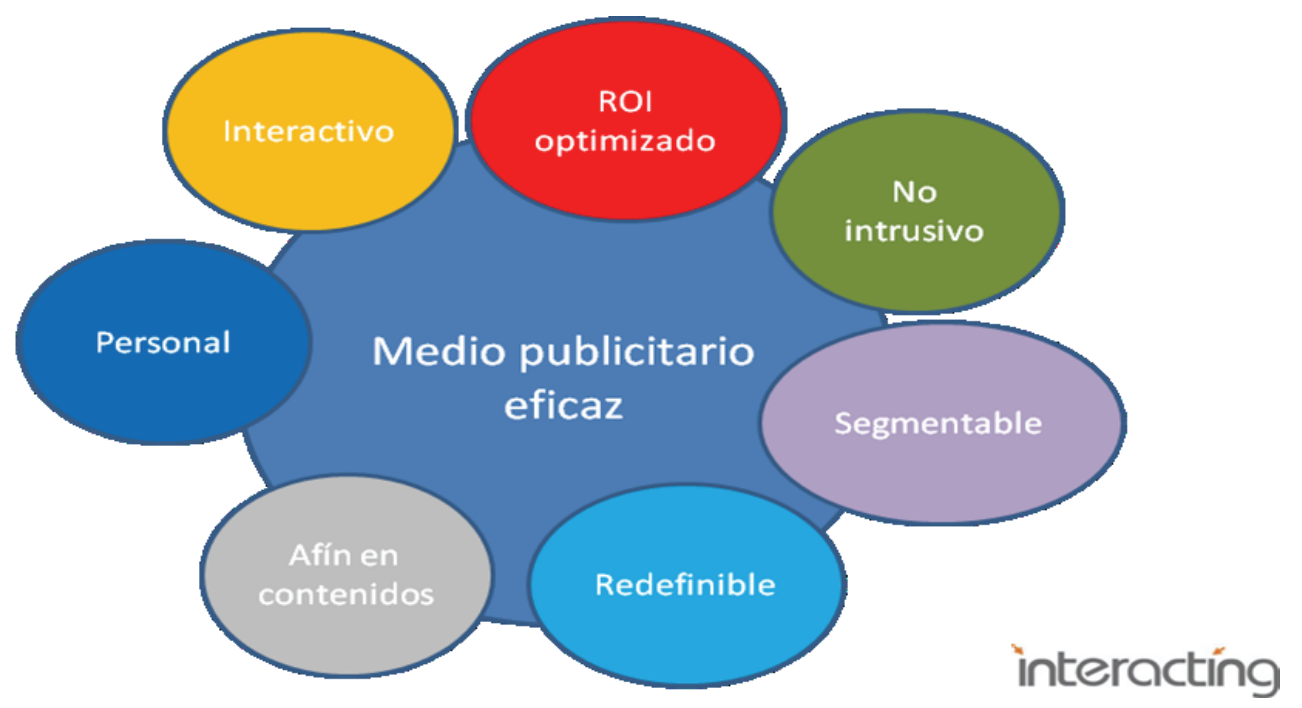


Este esquema proyecta las variables que definirían el medio publicitario eficaz y que vamos a considerar en relación con el teléfono móvil como medio publicitario.

No se trata de volver a realizar un análisis pormenorizado de cada una de las variables que llevamos viendo en este trabajo, pero si desde una perspectiva global hay que afirmar que el terminal móvil cumple con todas las características que designan al medio eficaz.

El teléfono móvil como medio publicitario se enfoca prioritariamente hacia segmentos de población joven, que son los que más se relacionan con los nuevos usos tecnológicos, pero sin olvidar que prácticamente cualquier usuario puede mandar o recibir un mensaje e indudablemente este mensaje puede tener una naturaleza persuasiva.

La eficacia del teléfono móvil como medio publicitario se basa en que es un instrumento de comunicación individual que permite desarrollar campañas de publicidad personalizadas y por tanto con un nivel de segmentación muy preciso, ya que las acciones no se dirigen a audiencias masivas, se dirigen a individuos identificados uno a uno. Sus ventajas como medio usable son destacadas por Venkatesh, Ramesh y Massey (2003).

Es un medio interactivo que permite un dialogo permanente con el receptor y que por tanto suministra una información de el muy precisa. Este conocimiento es el que permite elaborar unos contenidos muy afines, puesto que están desarrollados en función de los gustos y preferencias declarados por el receptor de la comunicación.

La exposición a los mensajes publicitarios en este medio se produce de una forma voluntaria ya que es el receptor el que da autorización a los mensajes para desplegarse en la pantalla de su terminal. Es un medio donde la publicidad no es intrusiva y en el que además se puede elegir el tipo de publicidad que se quiere recibir.

Evidentemente, el nivel de información que se tiene en todo el proceso permite controlar la eficacia de las acciones que se están desarrollando, corregir en tiempo real aquellos parámetros que no funcionan y potenciar los que funcionan. Es un medio de comunicación en el que las estrategias de comunicación publicitarias son redefinibles en tiempo real. El mobile marketing se puede adjetivar como altamente competitivo (Michael y Salter, 2006).

La información que ofrece el teléfono móvil en el desarrollo de las campañas es muy completa y culmina con su capacidad para dar datos muy precisos sobre el retorno de la inversión realizada (ROI). Para la industria publicitaria, el factor medición es esencial, puesto que los clientes quieren saber que obtienen a cambio de sus inversiones en publicidad. Gracias a la exacta información que suministra este nuevo medio, el ROI Return On Investment se obtiene con mucha precisión. Además, la relación inversión/resultados se optimiza al máximo, ya que los costes para realizar acciones publicitarias en el terminal móvil son sensiblemente inferiores a los de otros medios tradicionales.

Indudablemente, la publicidad va a seguir siendo multimedia y desarrollando campañas utilizando todos los medios a su alcance. Los estudios demuestran que el uso combinado de diferentes medios consigue ratios de eficacia mayores mediante la suma de los diferentes potenciales de cada uno de ellos.

Las prestaciones del teléfono móvil aumentan día a día gracias al constante avance tecnológico y la industria ya busca un estándar que permita unificar la base tecnológica y abrir el camino para que más empresas se centren en el desarrollo de aplicaciones que potencien las enormes posibilidades de estos terminales.

En conclusión, el teléfono móvil representa para la publicidad un nuevo canal con unas prestaciones que abren unas enormes posibilidades de explotación, y que basándose en 
el potencial de las nuevas tecnologías se postula como uno de los medios predominantes en el futuro a corto plazo. En la actualidad, el móvil es un medio con el que se puede acceder a infinidad de contenidos, incluyendo la web 2.0: mobile web 2.0 en el teléfono móvil (Jaokar y Fish, 2007).

\section{Diseño de la Investigación}

Este estudio pretende ser un primer paso de una investigación que se está desarrollando en este momento por un grupo de profesores del área de publicidad y alumnos doctorandos de la Facultad de CC. De la Información. El resultado de la primera fase está reflejado en este artículo.

\subsection{Objetivos}

1. Analizar el consumo publicitario en el móvil

2. Establecer cuáles son las perspectivas que se abren para la publicidad en relación con este nuevo medio.

3. investigar todos los parámetros publicitarios que se dan en este dispositivo.

4. Establecer cómo sus capacidades tecnológicas se utilizan para articular acciones de comunicación persuasiva.

La hipótesis de la que partimos es que el medio publicitario es un medio adecuado para desarrollar campañas de comunicación publicitaria.

Al inicio de la investigación se plantearon una serie de preguntas acerca del consumo publicitario en la telefonía móvil:

- 1. ¿̇Aceptan los consumidores recibir publicidad en el teléfono móvil?

- 2. ¿̇Entienden los mensajes publicitarios?

- 3. ¿Recuerdan la publicidad?

- 4. ¿Qué tipos de contenidos publicitarios prefieren?

- 5. ¿Qué vía de recepción valoran más positivamente?

Para llevar a cabo un análisis pertinente del objeto de estudio de este trabajo, se plantea realizar una metodología de investigación que utiliza técnicas cuantitativas. Esta fase va a ser la que nos permita lograr precisión en el análisis de los resultados y describir la relación estadística entre variables que dé respuesta objetiva a las preguntas planteadas. Más adelante, se realizará otra investigación de tipo cualitativo.

Mediante una encuesta de opinión analítica explicaremos cómo se relacionan los usuarios de teléfonos móviles con los usos publicitarios que se dan en su terminal.

Para conducir el estudio, se ha seleccionado una muestra no probabilística accesible formada por usuarios comprendidos entre 18 y 25 años. Este perfil se ajusta al segmento de usuarios que conforman el público objetivo de referencia por su relación con los medios de comunicación basados en las nuevas tecnologías. Este colectivo de "nativos digitales" responde estratégicamente al criterio de búsqueda de individuos familiarizados con el terminal móvil y sus contenidos.

Al grupo de referencia se le ha sometido a un cuestionario de respuesta cerrada de selección múltiple diseñado en base a la escala de Likert. Las preguntas persiguen que el encuestado muestre su grado de acuerdo o desacuerdo en una escala de 0 a 5 respecto a la propuesta planteada. Todas las preguntas incorporan para su medición aspectos 
relevantes de las variables en estudio. En cada pregunta, los encuestados sólo pueden elegir una opción.

Las preguntas persiguen conocer la opinión de los encuestados respecto a las siguientes variables:

1. Grado de aceptación de la publicidad en el teléfono móvil

2. Facilidad de recuerdo

3. Calidad informativa

4. Preferencia de contenidos

5. Preferencia en función de las vías de comunicación

6. Frecuencia de recepción

Para facilitar el cumplimiento del cuestionario, todas las preguntas están construidas de un modo que permita responderlas de forma sencilla. Aunque son muchas las áreas de interés que este aborda, se ha condensado al máximo para no provocar abandonos por ser demasiado extenso.

Se ha buscado una forma de entrevista que fuese operativa y directa, por lo que se ha realizado a través de internet en los meses de Mayo y Junio de 2009. El cuestionario se posicionó en la dirección: www.ucm.es/info/descargas/?movil Los datos obtenidos se verificaron mediante llamada telefónica.

Ficha de la investigación

\begin{tabular}{|l|l|}
\hline Encuesta de opinión: & analítica \\
\hline Muestra: & no probabilística, accesible, voluntaria, estratégica \\
\hline Cuestionario: & $\begin{array}{l}\text { respuesta cerrada, selección múltiple, escala de } \\
\text { Likert, opción única, sencillo (no abandonos) }\end{array}$ \\
\hline Tamaño muestral: & 84 entrevistas \\
\hline Forma: & internet \\
\hline Mecánica de seguimiento: & verificación mediante llamada telefónica \\
\hline
\end{tabular}

\section{Análisis e interpretación de los datos}

\section{Composición de la muestra por sexo (en \%)}

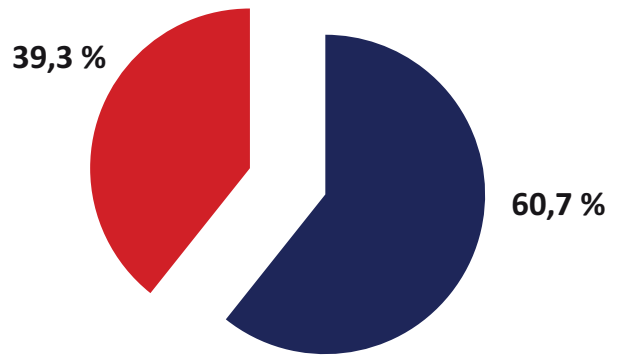

Femenino

Masculino

Fuente: Propia. 
Respecto al objeto de estudio, solo uno de los participantes en la encuesta declara no tener teléfono móvil. Por tipología de terminal, el 96,4\% tienen un modelo convencional y solo el 3,6\% son propietarios de un terminal inteligente. En cuanto a la edad en la que comenzaron a utilizarlo, 45 encuestados declaran haber empezado antes de los 15 años, 35 entre los 15 y los 18 años y 4 después de los 18.

\section{Edad de inicio de uso (número de individuos)}



Fuente: Propia.

La frecuencia de uso del teléfono móvil ofrece datos relevantes en relación con las diferentes funcionalidades. Observamos que el 41, 7\% de los encuestados llaman entre 1 y 5 veces al día, y este dato aumenta si nos referimos al envío de SMS y MMS, con un 42,9\% que envían de 1 a 5 mensajes diarios. El resto de funciones del terminal tienen un grado de uso mucho menor, lo que indica que el segmento de población joven utiliza básicamente el terminal para hablar y enviar mensajes. Sin embargo, hay que tener en cuenta que más del $14 \%$ de la muestra navega con el móvil por internet al menos una vez al día y que un $19 \%$ tienen conexión bluetooth permanentemente.

La tipología de contrato marca una clara preferencia por los servicios en la modalidad de contrato frente a los prepago.

\section{Tipología de servicio}



Contrato

Prepago

Fuente: Propia. 
Si habíamos visto que por tipo de terminal, la mayoría utilizan modelos convencionales frente a smartphones, encontramos que por tipo de conectividad no existe una definición clara hacia un sistema, aunque si una preferencia por conexiones de tercera generación.

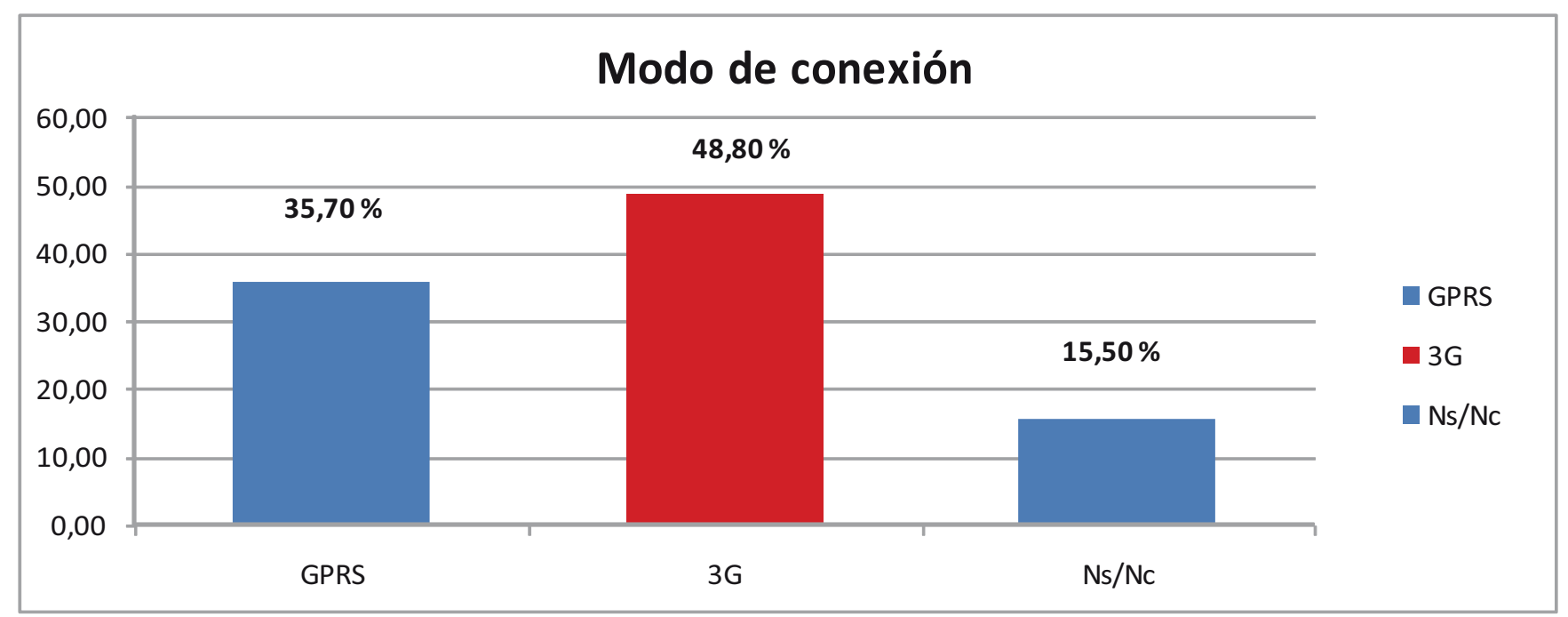

Fuente: Propia.

Resulta interesante constatar que 13 individuos no saben o no contestan a esta pregunta, lo que implica por su parte una escasa atención a una de las variables más importante en las prestaciones de la telefonía móvil. En cualquier caso, la conexión GPRS acabará por desaparecer a medio plazo, toda vez que los fabricantes solo ofrecerán terminales 3G que se puedan adaptar a los nuevos servicios disponibles a través de redes de alta velocidad.

\section{Características publicitarias}

Un $71,4 \%$ de los encuestados declara recibir mensajes publicitarios en el teléfono móvil. El $20,2 \%$ no reciben y un $8,3 \%$ no saben o no contestan.

\section{Reciben publicidad en el móvil (número de individuos)}

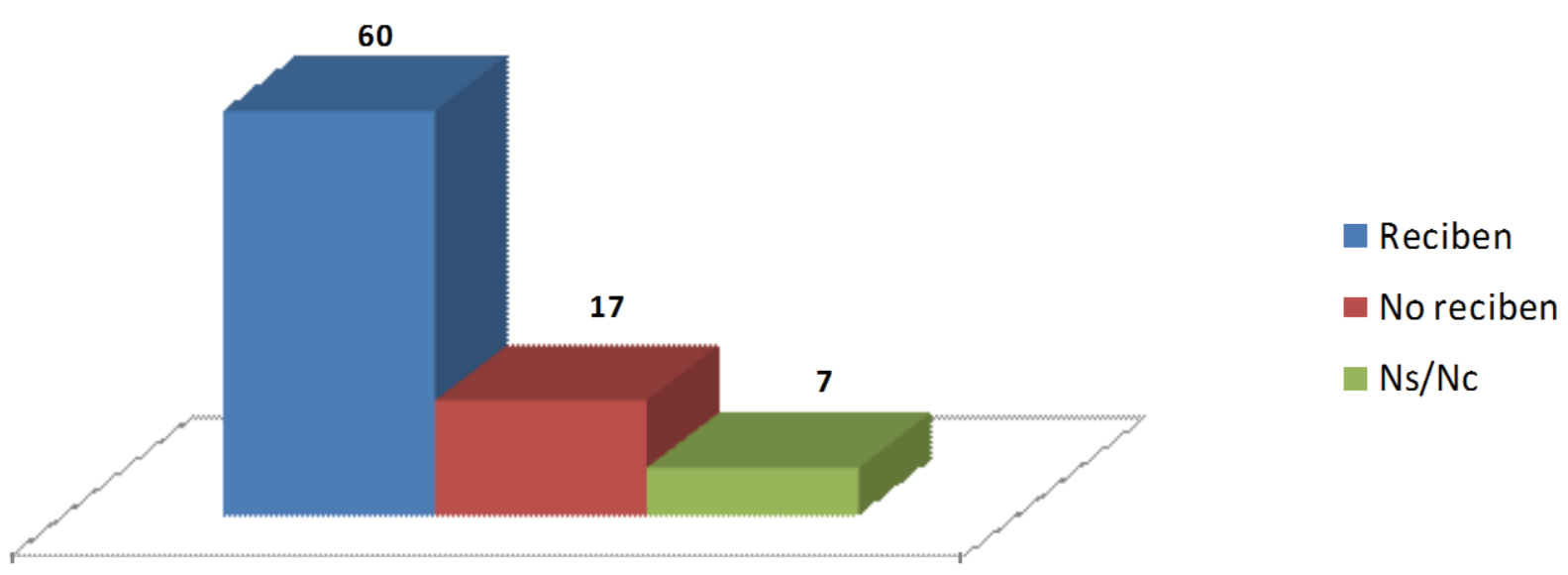

Fuente: Propia. 
La frecuencia de recepción de anuncios publicitarios varía según la forma en que llegan al terminal.

\begin{tabular}{|l|l|l|l|l|l|l|}
\hline & $\begin{array}{l}\text { NO } \\
\text { RECIBEN }\end{array}$ & BAJA & MEDIA & ALTA & MUY ALTA & NS/NC \\
\hline SMS & 3 & 3 & 9 & 13 & 25 & 31 \\
\hline MMS & 8 & 8 & 13 & 9 & 11 & 35 \\
\hline Llamada & 23 & 10 & 4 & 4 & 0 & 43 \\
\hline Blvetooth & 24 & 4 & 0 & 2 & 0 & 54 \\
\hline
\end{tabular}

Fuente: Propia.

Los datos recogidos en esta tabla nos revelan dos aspectos importantes sobre la publicidad en el móvil: en primer lugar, la principal vía de recepción es a través de mensajes SMS/MMS, en segundo lugar, el alto número de respuestas perdidas indica que los receptores no recuerdan el sistema de recepción, ya que como habíamos visto, el $71,4 \%$ reconoce recibir publicidad.

Los SMS/MMS no solo son el sistema más habitual para recibir publicidad, también son el medio preferido por los encuestados. Al 11,2\% de la muestra válida le gusta recibir SMS de carácter publicitario y al $9,4 \%$ los MMS. En este sentido, es interesante reflejar como son estos anuncios.

\section{Como son los anuncios recibidos (número de individuos)}

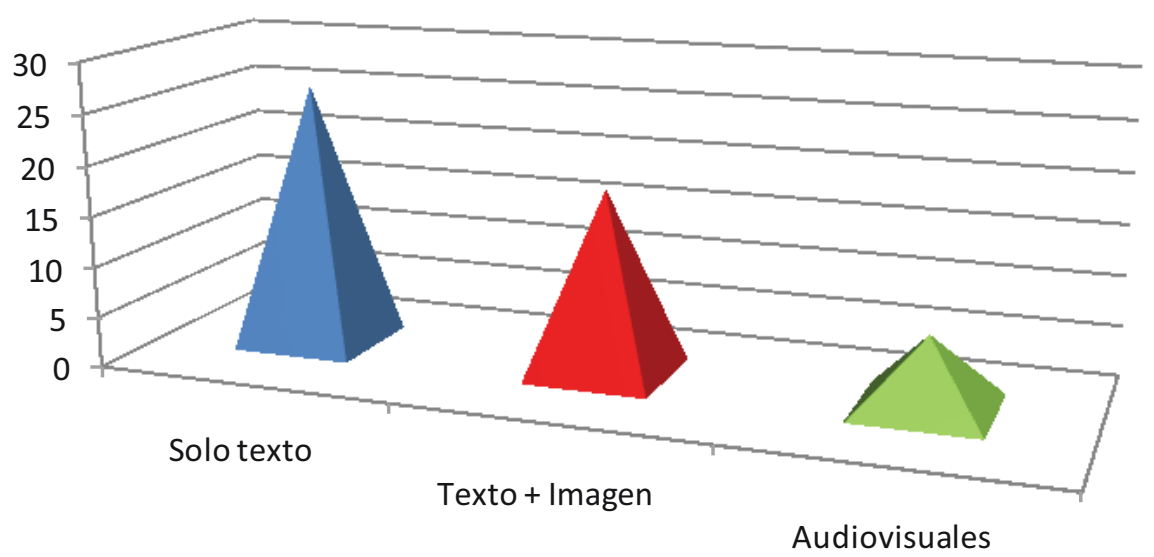

Fuente: Propia. Valor sobre muestra válida.

Los anuncios con ejecución audiovisual son los que más atraen a los encuestados y los que combinan texto e imagen son los valorados como los que transmiten con mayor calidad.

\begin{tabular}{|l|l|l|}
\hline & ATRACCIÓN & CALIDAD \\
\hline Texto & $11,7 \%$ & $19,2 \%$ \\
\hline Texto + imagen & $15,6 \%$ & $30,2 \%$ \\
\hline Texto + imagen + sonido & $20,0 \%$ & $22,5 \%$ \\
\hline Audiovisuales & $27,5 \%$ & $18,0 \%$ \\
\hline
\end{tabular}

Fuente: Propia. Valores sobre muestra válida. 
Los mensajes persuasivos, cuanto más multimedia son, más grado de aceptación tienen. Este parámetro no se cumple en el caso de la variable calidad informativa ya que los desarrollos audiovisuales están lejos de transmitir sus contenidos con la eficacia de los anuncios elaborados combinando texto e imagen.

El grado de recuerdo de los mensajes publicitarios en el móvil se ha estudiado desde la perspectiva formal y de contenido.

\section{Comparativa del grado de recuerdo en función del formato (en \%)}



- Texto + imagen

Texto + imagen + sonido

Audiovisuales

- Imagen

$23,10 \%$

Fuente: Propia. Valor sobre muestra válida por tipo de formato.

El formato más recordado es el audiovisual, aunque la diferencia con los anuncios que incorporan texto/imagen o texto/imagen/sonido es muy pequeña. Se puede afirmar, que estos 3 formatos son adecuados para realizar campañas publicitarias en el móvil. Es interesante reflejar el escaso grado de recuerdo que obtiene los mensajes que solo incorporan texto, sonido o imagen.

Grado de recuerdo en función del contenido (en \%)



Fuente: Propia. 
Los datos obtenidos manifiestan de manera rotunda que los anuncios que conllevan promociones interesantes son los más recordados. En segunda posición aparecen aquellos creados con un contenido gracioso, aunque este es un código que en muchos casos implica que el recuerdo del aspecto gracioso prevalece sobre el recuerdo de la marca. Hay que destacar, que a la hora de abordar el análisis de la variable recuerdo en relación con el formato o el contenido, un porcentaje elevado de los encuestados no contestan, lo que vuelve a reflejar la impresión de que todos se acuerdan de que reciben publicidad en el teléfono móvil, pero no son capaces de precisar el formato o el contenido.

La publicidad que más gusta recibir en el terminal es la que contiene promociones interesantes, que como hemos visto es también la más recordada. Parece claro que los encuestados se inclinan por aquellos mensajes publicitarios que de algún modo incorporan potenciales beneficios para los receptores.

En cuanto a cómo valoran la publicidad según la tipología de emisor, los encuestados son unánimes y un $17,8 \%$ declara que les interesa aquella publicidad general que les invita navegar por una web, y un 11,8\% prefieren cualquier tipo de publicidad que provenga de marcas comerciales conocidas.

Para concluir, aportaremos el dato válido más categórico: el 85,4\% de los encuestados rechazan todo tipo de publicidad que se articule vía llamada telefónica. Es molesta, intrusiva, inoportuna y es el único modo publicitario que genera un grado de rechazo elevado.

La metodología fundamentada en el análisis estadístico descriptivo basado en el programa SPSS (Statistical Package for the Social Sciences) se ha centrado en la exploración de los datos parametricos y no paramétricos obtenidos en la investigación. Para este estudio se ha fijado un nivel de probabilidad del 0,05.

A través de la construcción de tablas de contingencia se ha calculado el valor JlCuadrado de las diferentes variables sometidas a estudio. Esta descripción se centra en el análisis de las relaciones entre aquellas variables que han aportado resultados significativos para el objeto de este trabajo.

El primer objetivo del análisis ha sido conocer si existe relación constatable entre aquellos encuestados que declaran tener teléfono móvil y el grado en que aceptan recibir publicidad en el terminal. Los datos obtenidos mediante el test de Jl-Cuadrado, demuestran que se puede inferir que no hay una variación significativa, por lo que podemos afirmar que la posesión de un teléfono móvil no implica aspectos diferenciales a la hora de recibir publicidad en el grupo de referencia.

Comparando la frecuencia de recepción de mensajes publicitarios en el móvil que combinan texto e imagen con el grado de aceptación de publicidad, se demuestra estadísticamente con un valor Jl-Cuadrado de 21,443 y un grado de libertad de 12 que existe una variación significativa entre las variables. 
Frecuencia de recepción de anuncios que combinan texto e imagen

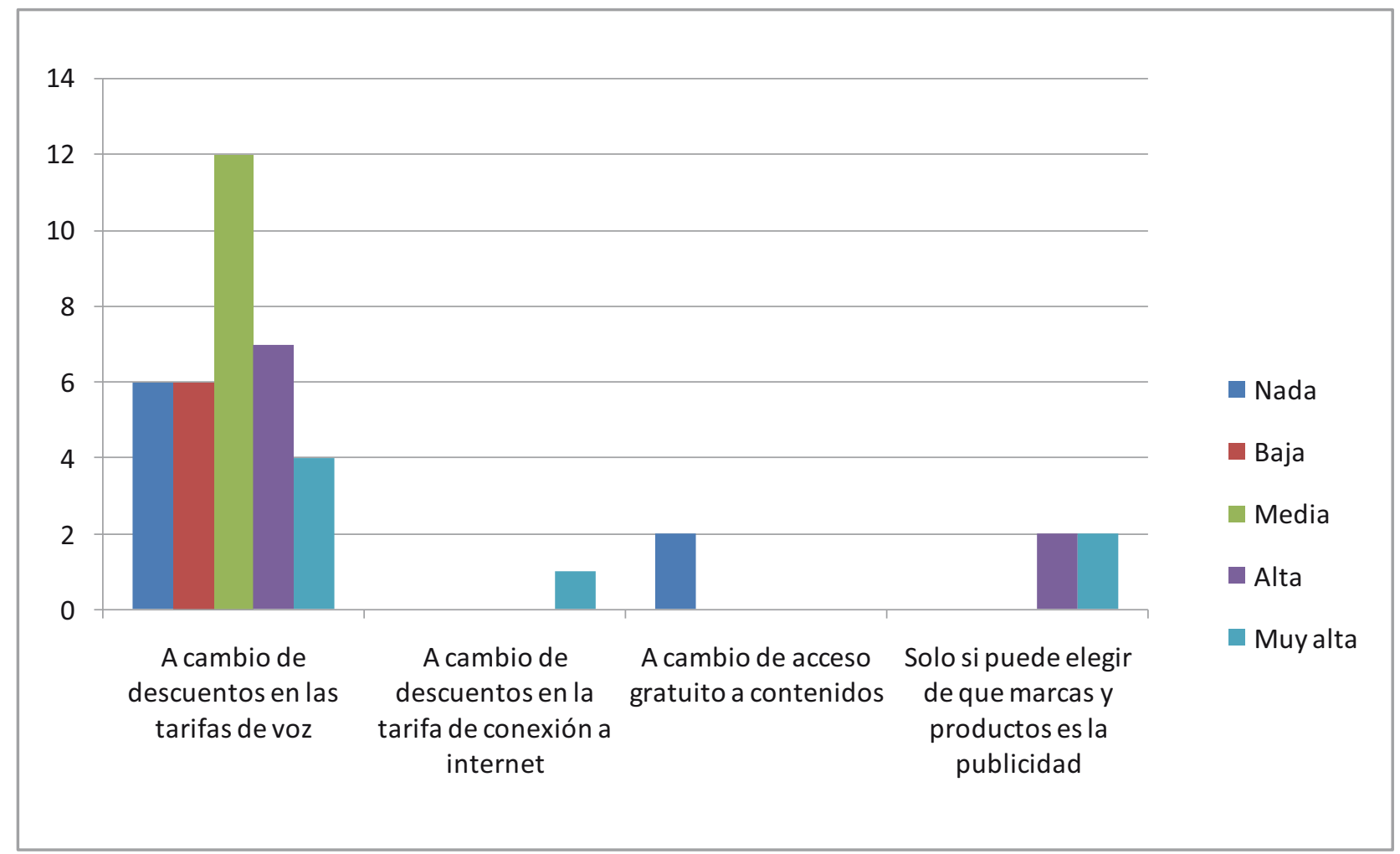

Fuente: Propia.

Los datos nos muestran que a cambio de descuentos en las tarifas de voz, los receptores de anuncios que combinan texto e imagen son los más predispuestos a recibir publicidad. Hay que destacar un dato relevante: aquellos que reciben con una frecuencia media aceptan mejor que aquellos que reciben con frecuencias altas o muy altas.

Para el análisis de datos paramétricos hemos utilizado la prueba "T" de Student y el análisis de varianza ANOVA.

Existe una variación significativa entre hombres y mujeres en cuanto al grado de recuerdo de anuncios publicitarios que solo incorporan texto ya que la prueba arroja un valor "T" de 2,145 para un grado de libertad de 39,819. 


\section{Anuncios con texto que recuerdan}



Fuente: Propia.

Estos datos, con una variación positiva, nos permiten inferir que las mujeres recuerdan más que los hombres los anuncios con texto.

En el caso de anuncios que solo incorporan sonido, también hay una variación significativa, con un valor "T" de -2,103 para un grado de libertad de 36.

\section{Anuncios con solo sonido que recuerdan}

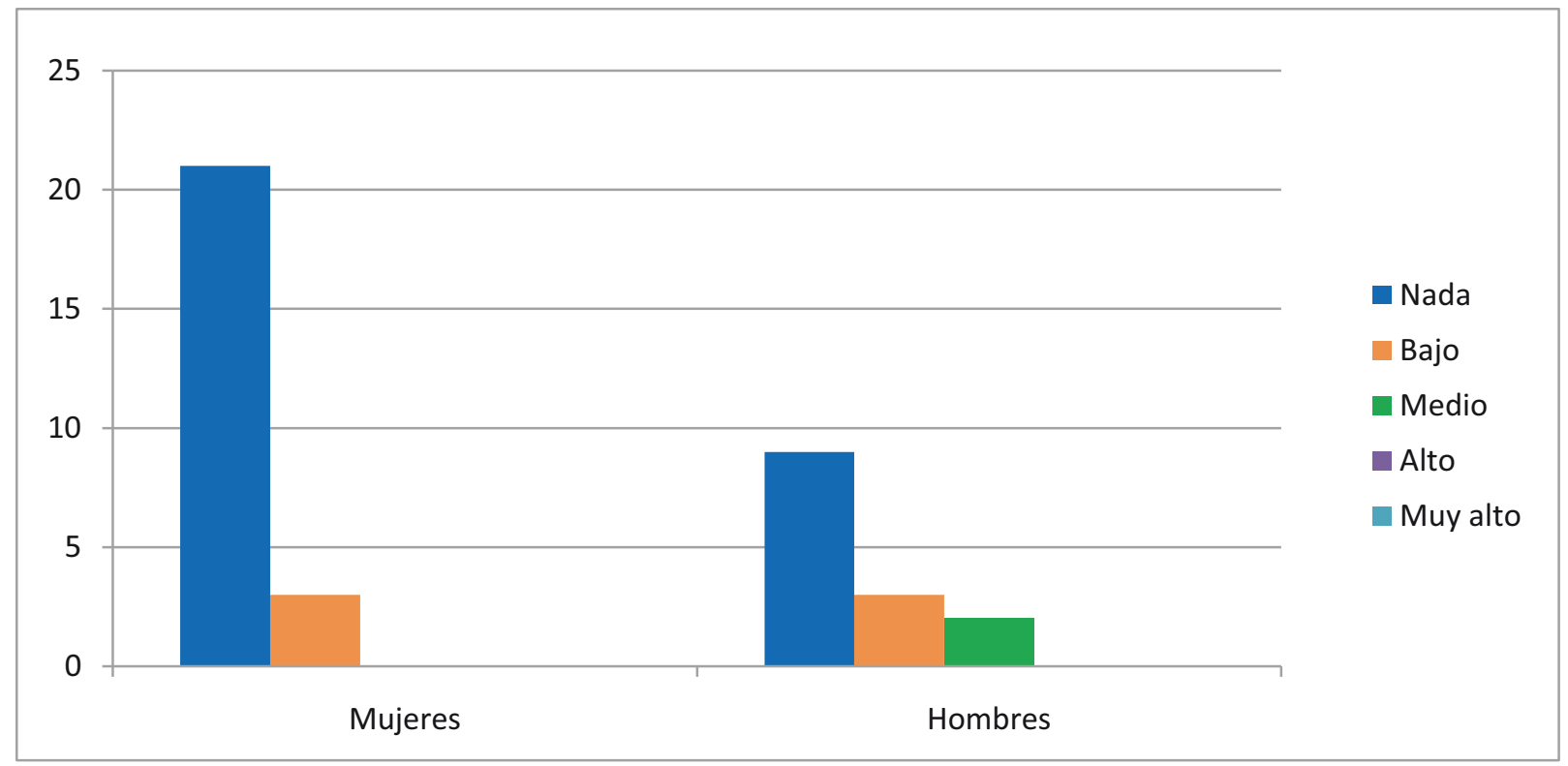

Fuente: Propia 
En el caso de anuncios producidos únicamente con sonido, observamos que la tendencia se modifica y son los hombres los que más recuerdan pues la variación muestra un valor negativo.

Si relacionamos el comportamiento de hombres y mujeres respecto a los anuncios en el teléfono móvil que incorporan solo texto o solo sonido, observamos que el tipo de formato puede condicionar el grado de recuerdo de los anuncios en función del sexo.

El ANOVA nos muestra que no hay variación significativa entre el grado en que gusta la publicidad en el móvil vía SMS y la frecuencia de recepción de anuncios vía SMS.

\section{Frecuencia de recepción de anuncios mediante SMS en relación con el grado en que le gusta la publicidad vía SMS}



Fuente: Propia.

Observamos que no hay variación significativa entre el grado en que se acepta la publicidad vía SMS y la frecuencia en que se reciben mensaje SMS, pues el valor "F" de ANOVA es de 1,441 para un grado de libertad 4 y 31, pero si podemos observar que los receptores de un mayor número de mensajes vía SMS, son los que muestran menos aceptan recibir, por lo que el uso de este tipo de mensajes en acciones de comunicación publicitaria para ser eficaz no debe saturar al receptor.

\section{Correlación de}

Del análisis de los datos relacionados con la variable "calidad informativa" de los anuncios publicitarios recibidos en el móvil se establece que existe correlación entre los datos. 


\section{Tabla de Correlación}

\begin{tabular}{|c|c|c|c|c|c|}
\hline & $\begin{array}{l}\text { Valor - } \\
\text { Calidad } \\
\text { informativa } \\
\text { de anuncios } \\
\text { publicitarios } \\
\text { que tienen } \\
\text { sólo imagen }\end{array}$ & $\begin{array}{l}\text { Valor - } \\
\text { Calidad } \\
\text { informativa } \\
\text { de anuncios } \\
\text { publicitarios } \\
\text { que tienen } \\
\text { sólo texto } \\
\end{array}$ & $\begin{array}{l}\text { Valor - } \\
\text { Calidad } \\
\text { informativa } \\
\text { de anuncios } \\
\text { publicitarios } \\
\text { que } \\
\text { combinan } \\
\text { texto e } \\
\text { imagen }\end{array}$ & \begin{tabular}{|l|} 
Valor - \\
Calidad \\
informativa \\
de \\
anuncios \\
publicitarios \\
que \\
combinan \\
texto, \\
imagen y \\
sonido \\
\end{tabular} & $\begin{array}{l}\text { Valor - Calidad } \\
\text { informativa de } \\
\text { anuncios } \\
\text { publicitarios } \\
\text { audiovisuales }\end{array}$ \\
\hline $\begin{array}{l}\text { Valor - Calidad } \\
\text { informativa de anuncios } \\
\text { publicitarios que tienen } \\
\text { sólo imagen }\end{array}$ & 1 &, $524(* *)$ & , $411\left(^{* *}\right)$ &, $342\left(^{*}\right)$ & 0,265 \\
\hline $\begin{array}{l}\text { Valor - Calidad } \\
\text { informativa de anuncios } \\
\text { publicitarios que tienen } \\
\text { sólo texto }\end{array}$ &, $524(* *)$ & 1 &, $854(* *)$ &, $596(* *)$ &, $550(* *)$ \\
\hline $\begin{array}{l}\text { Valor - Calidad } \\
\text { informativa de anuncios } \\
\text { publicitarios que } \\
\text { combinan texto e imagen }\end{array}$ &, $411(* *)$ & $854(* *)$ & 1 &, $773\left(^{* *}\right)$ &, $762(* *)$ \\
\hline $\begin{array}{l}\text { Valor - Calidad } \\
\text { informativa de anuncios } \\
\text { publicitarios que } \\
\text { combinan texto, imagen y } \\
\text { sonido }\end{array}$ &, $342\left(^{*}\right)$ &, $596\left(^{* *}\right)$ &, $773(* *)$ & 1 & $876(* *)$ \\
\hline $\begin{array}{l}\text { Valor - Calidad } \\
\text { informativa de anuncios } \\
\text { publicitarios audiovisuales }\end{array}$ & 0,265 &, $550\left(^{* *}\right)$ &, $762\left(^{* *}\right)$ &, $876\left(^{* *}\right)$ & \\
\hline
\end{tabular}

Fuente: Propia.

La evaluación de los datos obtenidos afirman que la muestra encuestada no encuentra calidad informativa en los anuncios publicitarios recibidos en el móvil, pues los cruces enseñan una alta correlación entre las variables que evalúan la calidad en relación con diferentes formatos, como vemos en la tabla anterior. 


\section{Calidad informativa de los anuncios audiovisuales en relación a los que combinan texto, imagen y sonido}

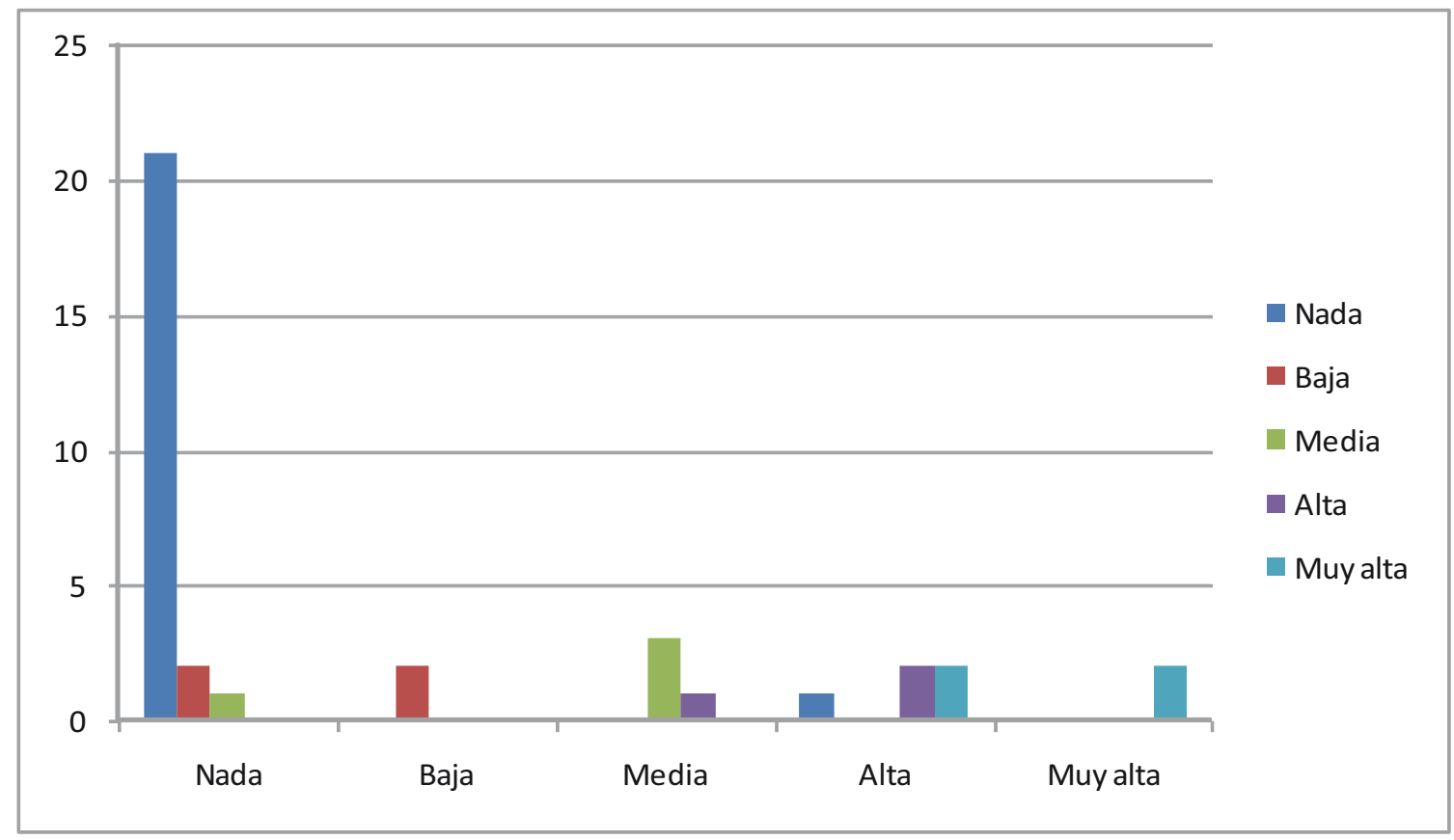

Valoración de la calidad informativa en anuncios audiovisuales

Valoración de la calidad informativa en anuncios que combinan texto, imagen y sonido

Fuente: Propia.

El gráfico es un ejemplo de cómo se comportan las variables, mostrando una alta correlación muy significativa en los que evalúan negativamente la calidad informativa de los anuncios que combinan imagen, texto y sonido y los audiovisuales.

Es importante reseñar que en este trabajo se han explorado aquellas variables que se centran en el objeto de estudio y sirven para verificar las hipótesis planteadas. No obstante, como se puede observar en los anexos, se han realizado otros análisis estadísticos descriptivos que ofrecen datos que abren vías para realizar otros estudios relacionados con el ámbito de la publicidad en el teléfono móvil que no se contemplan en esta investigación.

\section{Conclusiones}

\section{Los mensajes publicitarios en el móvil se recuerdan}

Los datos observados nos permiten afirmar que los mensajes publicitarios recibidos en el teléfono móvil que más se recuerdan son los producidos con formato audiovisual, aunque aquellos que combinan texto/imagen y texto/imagen/sonido alcanzan un grado de recuerdo también significativo dentro de la muestra analizada.

Por sexo, encontramos diferencias en el grado de recuerdo entre hombres y mujeres, ya que los hombres recuerdan más los anuncios textuales, mientras que las mujeres tienen más capacidad de recuerdo para los anuncios sonoros.

En cuanto al contenido, aquellos mensajes que incorporan ofertas promocionales o proponen descuentos interesantes son los que alcanzan un mayor grado de recuerdo. Los 
anuncios creados en código de humor también se recuerdan, pero con un nivel considerablemente inferior a los de contenidos promocionales.

El resultado verifica y confirma que los anuncios publicitarios en el móvil se recuerdan y que el grado de recuerdo está condicionado por el formato y el contenido.

\section{Los mensajes publicitarios con contenidos promocionales son los que más gustan}

Aquellos anuncios que incorporan en su contenido promociones que ofrecen descuentos en las tarifas de voz son los que más gustan a los encuestados. Estos mensajes alcanzan el mayor grado de preferencia cuando su ejecución combina texto/imagen.

Se confirma que los anuncios publicitarios en el móvil gustan, siendo los que combinan texto/imagen y contenido promocional los preferidos. De este modo, la propuesta de ventajas económicas en los mensajes se muestra como el contenido más atractivo para la muestra.

\section{Las campañas publicitarias vía SMS son las que mejor aceptan las audiencias}

La investigación nos ofrece datos con los que poder afirmar que el sistema de mensajería mediante SMS es la vía principal a través de la que los encuestados reciben publicidad en su terminal móvil. Para este segmento de población joven, el teléfono tiene una funcionalidad básica: enviar/recibir SMS, por lo que este sistema publicitario se muestra como idóneo por su afinidad.

Es importante resaltar que aquellos que reciben publicidad con una frecuencia media están más abiertos a recibir publicidad por SMS que aquellos que declaran recibir con una frecuencia alta o muy alta.

Los anuncios por SMS son los que mejor aceptan los encuestados.

\section{Los mensajes publicitarios en el móvil se comprenden}

Los datos obtenidos en la investigación confirman que los encuestados encuentran que muchos de los anuncios publicitarios que reciben en sus terminales móviles carecen de calidad informativa, por lo que sus contenidos no están claros y son difíciles de comprender.

\section{El teléfono móvil es un medio adecuado para desarrollar campañas publicitarias}

La verificación de las hipótesis particulares permiten afirmar que el teléfono móvil es un medio adecuado para la publicidad, ya que además de las características propias que hemos constatado que le definen como un medio personal, portátil e interactivo, aglutina condiciones particulares esenciales para la publicidad: los anuncios se recuerdan, los contenidos son eficaces y las vías de transmisión de los mensajes funcionan.

Como hemos comprobado, los mensajes persuasivos en el terminal móvil son notorios y eficaces, pero tienen que mejorar su comprensión por parte de los receptores. Sin embargo, este factor no depende tanto de las prestaciones como medio del teléfono móvil, como de la industria publicitaria que tiene que mejorar su elaboración y producir mensajes de mayor calidad.

En definitiva, se puede afirmar que el teléfono móvil es un medio adecuado para desarrollar campañas puesto que cumple eficazmente con parámetros esenciales para la comunicación publicitaria. 


\section{BIBLIOGRAFÍA}

AAVV. Estudio de inversion en marketing y publicidad móvil. MMA (Mobile Marketing Association). Madrid 2008.

AAVV. Tecnologías móviles. Apertura y nuevos modelos de negocio. Fundación de la Innovación Bankinter, Madrid, 2008.

AAVV, Ciudadanía móvil. Madrid: Manuales Plan Avanza 2008. Red.es

AAVV. Estudio Infoadex de la inversion publicitaria en España. Infoadex S.A., Madrid, 2008.

AAVV. Informe Anual CMT (Comisión del Mercado de las Telecomunicaciones).CMT; Barcelona, 2008.

AAVV. Gartner's Annual Update on Mobile Devices.Gartner Inc., Standford (EEUU), 2008.

AAVV. Libro blanco de los contenidos digitales en España. ONTSI (Observatorio Nacional de las Telecomunicaciones y la SI). Madrid, 2008.

AGUADO, J. \& Martínez, I. "El proceso de mediatización de la telefonía móvil: de la interacción al consumo cultural". Zer, 20, Universidad del País Vasco, Bilbao, Mayo (2006), pp. 319-343.

ARROYO, I. "La creatividad y la razón tecnológica en la argumentación publicitaria". Creatividad y Sociedad 6, Madrid (2004), pp. 27-34.

ARROYO, L. Tecnología Móvil. Anaya Multimedia, Madrid, 2003.

BAÑOS, M. "Internet żuna puerta abierta a la publicidad?" Icono 14, num 3. Madrid, Junio (2004). http://www.iconol4.net/revista/num3/art4/Internet MIGUEL BANOS.pdf (acceso noviembre 2009

BARNES, S.J. and Scornavacca, E. (2004): "Mobile Marketing: The Role of Permission and Acceptance", International Journal of Mobile Communications, Vol. 2, No. 2: 128-139.

CANO, I. "Las tres pantallas como plataforma publicitaria". IPMark 718, Madrid (2009), p.50.

CARR, R. "The Role of NSF's Support of Engineering in Enabling Technological Innovation". The National Science Foundation. IV, Virginia, EEUU, Julio (1998), p. 83.

CARRILLO, Ma. V. y Castillo, A. "La Nueva Publicidad Digital (NPD): Servicios Digitales y Contenidos Interactivos que Generen 'Experiencias' en los Consumidores". Razón y Palabra, 45. México, Junio/Julio (2005).

http://www.www.razonypalabra.org.mx/anteriores/n45/index.html (acceso noviembre 2009)

CARRILLO, Ma.V. "La televisión digital. La metamorfosis publicitaria en el mercado interactivo".

Telos, n 62, Madrid, Enero-Marzo 2005

CARRILLO, $M^{a}$.V. "La interactividad: un reto para la publicidad en el entorno digital online". 
Zer, $n^{\circ} 18,2005$.

CREMADES, J. La crisis de las "punto.com" en España. Madrid, 2001: E-business Center PwC \& IESE.

CUESTA, U. Psicología Social Cognitiva de la Publicidad. Editorial Fragua. Madrid, 2004.

DAVIS, F. y Venkatesh, V. "User acceptance of computer technology: a comparision of two theoretical models". Management Science Magazine. 35, University of Pennsylvania, Filadelfia (EEUU), Agosto (1989), pp. 982-1003.

DUCOFFE, R. H. "How Consumers Assess the Value of Advertising". Journal of Current Issues and Research in Advertising 17/1, New York (EEUU), Primavera (1995), pp. 1 - 18.

DUDERSTADT, J. Higher education in the digital age. Washington, (EEUU), 2002. American Council on Education y Praeger Publishers.

EGUIZÁBAL, R. Teoría de la publicidad. Ediciones Cátedra. Madrid, 2007

GARCÍA, M. Las claves de la publicidad. Escuela Superior de Gestión. Madrid,1997

GARCÍA. F. Estrategias creativas. Ministerio de Educación y Ciencia y Ediciones Vicens Vives, S.A. Madrid, 1991.

GIL, A. "¿Nuevas tecnologías de la información y la comunicación o nuevas tecnologías de relación? Niños, jóvenes y cultura digital", 2004. http://www.voc.edu/dt/20347

GROEBEL, J. y Noam, E. y Feldmann, V. Mobile Media. Content and Services for Wireless Communication. Mahwah (NJ): Lawrence Erlaboum Associates. 2006.

GYE, L. "Picture This: the Impact of Mobile Camera Phones on Personal Photographic Practices". Journal of Media \& Cultural Studies. 21, Nueva York, Junio (2007), pp.279-288.

HAGHIRIAN, P. and DICKINGER, A. (2004): "Identifying SuccessFactors of Mobile Marketing", ACR Asia-Pacific 2004 (Association of Consumer Research).

ITO, M. y Okabe, D. y Matsuda, M. Personal, Portable, Pedestrian: mobile phones in Japanese life. Cambridge (Mass, 2005): MIT Press.

ITO, M. "A new set of social rules for a newly wireless society", en Japan Media Review, 2003. 200http://www.ojr.org/japan/wireless/1043770650.php (acceso octubre 2009).

JOHNSON, S. Interface culture. How new technology transforms the way we create and communicate. San Francisco (CA), (1997): Harper Edge.

LING, R. The mobile connection: the cell phone's impact on society. San Francisco (CA) (2004): Morgan Kaufmann Publishers.

INFORME ANUAL. Los medios digitales en España y Portugal. Editado por el departamento de investigación de ZenithOptimedia. Madrid, 2008. 
MCLUHAN, M. Comprender los medios de comunicación. Las extensiones del ser humano. Editorial Paidós. Barcelona, 1996.

MICHAEL, A. \& SALTER, B. (2006): "Mobile Marketing: Achieving Competitive Advantage through Wireless Technology". Elsevier. Oxford (UK).

NAISBITT, J. Megatrends 2000. Nueva Cork, 2000: Avon Books.

INFORME Navegantes en la red. AIMC (Asociación para la Investigación de Medios de Comunicación), Madrid, 2009.

JAOKAR, A. \& FISH, A. (2007): "Mobile web 2.0". Fututretext Publications. Oxford (UK).

NEGROPONTE, N. El Mundo Digital: El futuro ha llegado. Colección Biblioteca de Bolsillo (ITACA). Barcelona, 2000.

OGILVY, D. Ogilvy on advertising. Vintage Books. Nueva Cork, 1995.

OTERO, M.D. "A propósito de la telefonía móvil. Una reflexión desde la perspectiva de la psicología individual y social". Ámbitos. Revista de Comunicación Social Universidad de Sevilla, 47 (5), Sevilla, Febrero (2002), pp 211-235.

PÉREZ A. "El servicio de Telefonía Móvil en España". Foro Histórico de las telecomunicaciones. Colegio Oficial de Ingenieros de Telecomunicaciones. Madrid, 2006.

PRENSKY, M. "Digital natives, digital immigrants". en On the Horizon 9(5), Devon (UK), octubre (2001) pp. 1-6. y en http:// www.marcprensky.com/writing/ (acceso septiembre 2009)

ROGERS, E.M. Diffusion of Innovations. New York Press. New York, 1962.

SÁNCHEZ, J.R. Breve historia de la publicidad. Ed. Ciencia 3. Madrid 1989.

SHARMA, C. y Herzog, J. y Melfi, V. Mobile Advertising: supercharge your brand in the exploding wireless market. New Jersey: Wiley, 2008.

STONE, B. Marketing Directo: métodos para alcanzar el éxito. Barcelona: Asociación española de Marketing directo (AEMD). Barcelona, 1988.

VENKATESH, V., RAMESH, V. and MASSEY, A. P. (2003): "Understanding Usability in Mobile Marketing", Communications of the ACM 46(12), 2003, pp. 53 - 56.

TREJO, R. Viviendo en el aleph. La sociedad de la información y sus laberintos. Gedisa.

Barcelona, 2006.

VERSCHUEREN, J. "Para entender la pragmática". Editorial Gredos, Madrid, 2002.

WATSON, I. y Lightfoot, D. J. "Mobile working with connexions" en Facilities 21. 2003.

http://www.emeraldinsight.com/0263-2772.htm (acceso octubre 2009)

WIMMER, R. y Dominick, J. La investigación científica de los medios de comunicación. Bosh Casa Editorial. Barcelona, 1996. 
WORLD CELLULAR INFORMATION SERVICE. International Telecommunication Union:

"Worldwide mobile cellular subscribers to reach 4 billion mark late 2008".

http://www.itu.int/newsroom/press_releases/2008/29.html

YOUNG, A y Aitken, L. Profitable Marketing Communications: a guide to marketing return on investment. Londres (2007): Kogan Page Limited. 